\title{
Role of EG-VEGF in Human Placentation: Physiological and Pathological Implications
}

\author{
P. Hoffmann, S. Brouillet, M. Benharouga, J.J. Feige and N. Alfaidy \\ University Joseph Fourier, INSERM U1036, CEA - Grenoble,
}

France

\section{Introduction}

Pre-eclampsia (PE, also called gravidic toxemia) is a hypertensive disorder that affects $5 \%$ of all pregnancies. It occurs during the second half of pregnancy (Carty et al, 2010). Affected women experience high blood pressure, fluid retention, nausea, and headaches. If not treated, PE leads to convulsions (eclampsia), kidney failure, liver failure and death. Screening tests for PE are poorly predictive and the "gold standard marker" is still to be discovered in order to assist the clinician in the prognosis of the pathology. The underlying causes of the development of the pathology are often unknown and the late diagnosis of the disease results in premature delivery of the fetus, which is considered to be the most definitive method to minimize PE complications. PE is still a major problem in Obstetrics and Gynecology and is the cause of several maternal deaths.

$\mathrm{PE}$ is a multifactorial disease whose pathogenesis is not solely vascular, genetic, immunologic, or environmental, but is a complex combination of factors (Ilekis et al., 2007). The heterogeneity of the disease is suggested by diverse clinical manifestations such as mild or severe PE, early onset ( $<34$ weeks) or late onset ( $>34$ weeks) of the disease and presence or absence of associated IUGR (intrauterine growth restriction) (Dekker, 1999). Also women with asthma, obesity, maternal infections, insulin resistance or adverse lipid metabolic profile have an increased incidence of PE. (Carty et al., 2010) Moreover, a population-based cohort study suggests that women with early-onset PE are at greater risk of cardiovascular disease later in life (Irgens, 2007). Although its aetiology remains unclear, there have been significant advances in the understanding of the pathophysiology of the disorder. The primary lesion is thought to be due to deficient trophoblast invasion of the maternal spiral arteries by the end of first trimester of pregnancy and the beginning of the second trimester, leading to underperfusion of the uteroplacental unit. It is well documented today that the cause of the development of PE is a shallow invasion of maternal decidua and spiral arteries by extravillous trophoblasts (EVTs) (Fisher, 2004, McMaster et al., 2004). Successful human placentation depends on adequate transformation of the uteroplacental vasculature by EVT following proliferation, migration, and invasion of these cells into the maternal decidua (Cross et al., 1994, Strickland \& Richards, 1992), this process of vascular remodeling rises to a peak by the end of the first trimester and declines rapidly thereafter (Aplin, 1991). At around 10-12 weeks of gestation (wg), cytotrophoblasts (CT) that are present in anchoring villi generate multilayered columns of EVTs that colonize the interstitium of the maternal 
decidua, the inner third of the myometrium and the uterine blood vessels. This invasion results in the formation of a low resistance vascular system that is essential for fetal growth (Charnock-Jones et al., 2004). This developmental period is characterized by an important physiological switch in oxygen tension during the opening of the intervillous space. Before 9 $w g$, placental oxygen tension is low $(\sim 20 \mathrm{~mm} \mathrm{Hg})$ and after the first trimester, it increases to $\sim 55 \mathrm{~mm} \mathrm{Hg}$ (Jauniaux et al., 2000). During pregnancy, the depth of invasion by EVT into the uterine wall is critical and finely controlled. Poor invasion causes a lack of remodeling of the spiral arterioles and leads to a sustained hypoxic environment over the first trimester of pregnancy. This abnormal condition potentially leads to pathological conditions such as PE, IUGR, spontaneous abortion and stillbirth (Carty et al., 2010, Myatt \& Miodovnik, 1999, Redman \& Sargent, 2005). For instance, a limited trophoblast invasion of maternal vessels has been correlated to both PE (Sibai et al., 2005) and fetal growth restriction, whereas an excessive trophoblast invasion is associated with invasive mole, placenta accreta and choriocarcinoma (Wells, 2007).

In PE, several aspects have been reported to contribute to the poor remodeling of the spiral arteries, including defective EVT differentiation toward the invasive phenotype, increased apoptosis, an imbalanced control of migratory and invasive EVT functions (Huppertz \& Peeters, 2005, Kingdom et al., 2000). However, despite many years of extensive research on the disorders that are associated with abnormal placentation, the mechanisms leading to a successful pregnancy are far from being fully understood. It is likely that a fine balance between the expression of pro- and anti-invasive factors might regulate the depth and rate of placental invasion. Various growth factors and cytokines, such as EGF, HGF, TGF- $\alpha$, amphiregulin, IGF-II, and IL-1 $\beta$, stimulate trophoblast differentiation toward an invasive phenotype (Cartwright et al., 1999,Lysiak et al., 1993); by contrast, limited data exist regarding possible negative regulators of trophoblast differentiation. Graham and Lala, (Graham \& Lala, 1991) first demonstrated that TGF- $\beta$ produced primarily by the decidua inhibits trophoblast invasion. Subsequent studies revealed that TGF- $\beta 3$ inhibits trophoblast invasion following an interaction with endoglin, a component of the TGF- $\beta$ receptor complex (Caniggia et al., 1997, Irving \& Lala, 1995). Recently, improved understanding of the pathogenesis of PE has raised the possibility that blood levels of antiangiogenic proteins might eventually be used to predict this devastating condition. Investigations on the cause of PE development have also pointed out the potential importance of angiogenic factors and their receptors. For instance, low VEGF (vascular endothelial growth factor) levels or increased production of VEGF antagonists such as the soluble fms-like tyrosine kinase-1 (sFlt-1, also referred to as sVEGFR-1) have been proposed as possible mediators of PE (Levine et al., 2004). A key discovery in the field was the understanding that PE major phenotypes, such as hypertension and proteinuria are due to an excess of sFlt- 1 that is made by the placenta and acts by neutralizing the pro-angiogenic proteins (VEGF) and placental growth factor (PlGF). More recently, soluble endoglin, another circulating anti-angiogenic protein was found to synergize with sFlt-1 and to contribute to the pathogenesis of PE. Abnormalities in these circulating angiogenic proteins are not only present during clinical $\mathrm{PE}$, but seem also to antedate clinical symptoms by several weeks. Altogether these findings suggest that sequential angiogenic factor changes could have predictive value in PE. Therefore, current research in this field aims to discover more specific markers of the disease. 
Although VEGF is selectively acting on any type of endothelial cell including placental endothelial cells, it is ubiquitously expressed. The existence of organ-specific angiogenic and/or anti-angiogenic factors has been postulated for many years (Dellian et al., 1996, Stewart \& Wiley, 1981), but only recently received confirmation when a new factor named endocrine gland-derived vascular endothelial growth factor (EG-VEGF), was characterized and sequenced (LeCouter et al., 2001). This factor was found to be expressed in testis, adrenal gland, ovary and placenta (LeCouter et al., 2001), in addition, its angiogenic action appeared to be restricted to endothelial cells derived from endocrine tissues (LeCouter et al., 2001). In endothelial cells isolated from steroidogenic tissues, EG-VEGF was shown to promote proliferation, survival and chemotaxis (LeCouter et al., 2001). In vivo delivery of adenoviruses encoding EG-VEGF resulted in endocrine tissue-specific angiogenesis (LeCouter et al., 2003).

EG-VEGF also called prokineticin 1 (PROK1) is a member of a class of proteins named prokineticins (PROK) family that also includes Bv8, a frog peptide purified from the skin secretion of the yellow-bellied toad Bombina variegata (LeCouter et al., 2001), also known as prokineticin-2 (PROK2). Human EG-VEGF and Bv8 share the same G protein-coupled receptors, termed PROKR1 and PROKR2 (Masuda et al., 2002).

\section{Prokineticins}

The Prokineticin family comprises EG-VEGF/PROK1 and Bv8/PROK2, which were identified in frog, fish, reptiles and mammals. The names PROK1 and PROK2 were assigned to these proteins by $\mathrm{Li}$ et al. (M. Li et al., 2001) to reflect their functions in inducing specific and potent contractions of the smooth muscle of the gastrointestinal tract. Subsequently, LeCouter et al. (LeCouter et al., 2001) described a growth factor which induced a strong and specific mitogenic response in endocrine gland-derived endothelial cells. The similar effects induced by this protein and by VEGF led it to be named, EG-VEGF. Although there are several similarities in the functions of VEGF and EG-VEGF, the two factors are structurally unrelated. EG-VEGF and Bv8 share 44\% amino acid identity and share a common protein structure motif. They have a conserved N-terminal sequence (AVITGA), which is essential for the activity of these proteins. Mutations to this sequence, by insertion of a methionine preceding the Nterminal alanine, substitution of the N-terminal alanine with a methionine or deletion of the first two amino acids (Negri et al., 2005), produce PROK receptor (PROKR) antagonists. Another feature of the PROKs is the presence of ten conserved cysteines, which are predicted to form five disulfide bonds (Boisbouvier et al., 1998, M. Li et al., 2001). The PROKs are the cognate ligands for two closely related G-protein-coupled receptors (GPCRs), termed PROKR1 and PROKR2, which share $85 \%$ amino acid identity and exhibit the greatest differences in their N-terminal sequences (D.C. Lin et al., 2002, Masuda et al., 2002). Their sequences are almost identical in the transmembrane domains (Soga et al., 2002), suggesting that their activation mechanisms are identical and that small molecule analogues will not discriminate between the receptors, as is the case for EG-VEGF and Bv8. The affinity of these factors for their receptors is similar, with Bv8 showing a moderately higher affinity for both receptors. PROKRs have been reported to couple either to Gs, Gi or to Gq proteins (D.C. Lin et al., 2002, Soga et al., 2002). In adrenal cortex capillary endothelial (ACE) cells, activation of the receptors has been shown to be inhibited by pertussis toxin, suggesting Gi coupling. By contrast, in transfected $\mathrm{CHO}$ cells activation of the receptors has been shown to induce calcium mobilization and phosphoinositide hydrolysis (D.C. Lin et al., 2002, Soga et al., 
2002), suggesting Gq coupling. Signalling through these receptors is linked to phospholipase $\mathrm{C}$ activation and generation of diacylglycerol and inositol phosphate, with potential downstream activation of protein kinase $C$, extracellular-signal regulated kinases (ERK) 1 and 2, Akt and nitric oxide synthase (Hoogerwerf, 2006,D.C. Lin et al., 2002,R. Lin et al., 2002).

\section{Prokineticins in reproduction}

Prokineticins were originally identified as regulators of intestinal contraction but subsequently shown to affect vascular function, neuronal survival, nociception, immune responses, and gonadotropin releasing hormone systems (Battersby et al., 2004, Dorsch et al., 2005, LeCouter et al., 2003, Maldonado-Perez et al., 2007). Quickly after their discovery, the members of this family showed differential specificities of expression and preferential sites of actions. While Bv8/PROK2 was associated to the neuronal system, EG-VEGF was more associated to the reproductive tract. EG-VEGF has been well studied in the ovary, uterus, testis, prostate and placenta (Battersby et al., 2004, Brouillet et al., 2010, Dorsch et al., 2005, Fraser et al., 2005,Hoffmann et al., 2007,2006, Hoffmann et al., 2009, LeCouter et al., 2001, LeCouter et al., 2003, Maldonado-Perez et al., 2007, Pasquali et al., 2006).

\subsection{Prokineticin expression in human reproductive systems}

Since its discovery, EG-VEGF has been reported to be highly expressed in the reproductive system, and it is now believed to play important roles in diverse facets of reproduction processes. While our group has been interested in the study of EG-VEGF and its receptors in the placenta, other groups have studied this factor in endometrium, ovary, prostate, uterus and testis.

In the testis, EG-VEGF is predominantly expressed in testosterone-producing Leydig cells, and its receptors are expressed in vascular endothelial cells (LeCouter et al., 2001). The exact role of each type of receptor remains however to be elucidated.

In the normal ovary, EG-VEGF is expressed in a dynamic way in elements of the sex cordstroma lineage. Maturing secondary follicles maintain strong EG-VEGF expression. However, in the antral follicle, EG-VEGF is expressed at low levels in theca cells. In the corpus luteum, the mRNA expression of EG-VEGF increases as the corpus luteum matures. The actions of EGVEGF in the ovary are likely to be mediated by both PROKR1 and PROKR2.

In the endometrium, EG-VEGF, PROKR1 and PROKR2 expression peak during the window of implantation, a period that corresponds to the maximum of receptivity, and there is no temporal variation in the expression of PROK2, PROKR1, or PROKR2 during the same period. EG-VEGF and its receptors were localized to multiple cellular compartments, including glandular epithelial, stromal, endothelial cells in the endometrium and endothelial and smooth muscle cells in the myometrium. The elevation in EG-VEGF expression in the secretory phase of the menstrual cycle indicated a potential regulation of EG-VEGF by progesterone (Fraser et al., 2005, Kisliouk et al., 2003).

Further support for a role of PROKs in reproductive functions can be gleaned from PROKR2 and PROK2 knockout mice, which show hypoplasia of the reproductive tract (Dode et al., 2006, Martin et al.). This phenotype has been explained by the lack of GnRH neurons in the 
hypothalamus of these animals. Interestingly, mutations in PROK2 and PROKR2 have been identified in patients with Kallmann syndrome, a pathology that is defined by the association of hypogonadotropic hypogonadism $(\mathrm{HH})$ with olfactory abnormalities (anosmia or hyposmia). Recently, homozygous loss-of-function mutations of PROK2 were described in families with $\mathrm{HH}$, suggesting an autosomal recessive inheritance disorder. Hence PROKs seem to be directly involved in a major pathology of the reproductive system that is due to failure in sexual maturation. However, it is possible that the loss of PROKs might also have a direct local impact on to the observed atrophy of these tissues.

\subsection{Prokineticins in human placenta and decidua}

In the placenta, the expression of EG-VEGF was briefly reported by the group of Ferrara in 2001. However, insightful work on EG-VEGF throughout pregnancy came from our group with a focus on early pregnancy and from the group of Dr Jabbour with more focus on the decidual unit, at the term of human gestation (Catalano et al., 2010 , Maldonado-Perez et al., 2007).

\subsubsection{Prokineticins at term of the pregnancy}

The group of Jabbour (Cook et al., 2010,Evans et al., 2008, Maldonado-Perez et al., 2007) has reported the localization of EG-VEGF and that of its receptors in term placenta and decidua; studied its signaling pathways, and demonstrated the effect of EG-VEGF on the expression of two inflammatory and vascular mediators, the cyclooxygenase (COX)-2 and IL-8 in thirdtrimester placentas. IL- 8 is a potent neutrophil chemoattractant and angiogenic factor, promoting endothelial cell chemotaxis (Winkler, 2003), whereas COX-2 is the inducible isoform of the enzyme involved in the synthesis of prostaglandins from arachidonic acid. Their results showed that EG-VEGF and PROKR1 were highly expressed in term placenta and were immunolocalized to syncytiotrophoblasts, cytotrophoblasts, fetal endothelium, and macrophages. EG-VEGF induced a time-dependent increase in the expression of IL-8 and COX-2. These data suggest that EG-VEGF may have a novel role as a mediator of the inflammatory response in the placenta at the time of parturition.

\subsubsection{Prokineticins in early pregnancy: focus on the placenta}

As mentioned above, among the prokineticin members, EG-VEGF appeared to be an important actor for reproductive functions with indications of its potential involvement in human pregnancy, and particularly in placentation processes. The next paragraphs will summarize our main findings in this field.

\subsubsection{Hypothesis}

EG-VEGF was shown to be specific of the reproductive system and to be highly expressed in the placenta. Since its levels of expression were up-regulated by hypoxia, a strong attribute of placentation processes; and since a predictive marker for the launch of PE is still to be discovered; we performed a series of investigations to determine whether EG-VEGF could be a such marker.

\subsubsection{Methods}

To investigate the role of EG-VEGF in normal and pathological pregnancies, we used both human and mouse material. This consisted of placental tissues and sera collected at different 
gestational ages. First-trimester human placentas were obtained from elective terminations of pregnancies. Shortly after collection, tissues were snap-frozen in dry ice and stored at $-80^{\circ} \mathrm{C}$ (for protein and mRNA extraction), fixed in paraformaldehyde at room temperature (for immunohistochemistry), or used for in vitro primary culture. Collection and processing of human placentas was approved by the University Hospital Ethics Committee, and informed consent was obtained from each patient (Brouillet et al., 2010, Hoffmann et al., 2007, 2006, Hoffmann et al., 2009). Mouse placentas were also collected at different gestational ages. Animal surgery was conducted following both institutional and European Community guidelines for the use of experimental animals.

To test our hypotheses, different methods were used. The main ones will be emphasized in each paragraph.

\section{Main results}

\subsection{Expression of prokineticins in human and mouse placenta}

Our first study on prokineticins in the placenta has reported the pattern of expression of EGVEGF and its analog, Bv8 (PROK2). This set of experiment has been performed using immunohistochemistry and western blot analysis. Whereas no expression of Bv8 was observed in the placenta, EG-VEGF was highly present in this tissue during the first trimester of pregnancy, with a strong expression in the syncytiotrophoblast. A comparison of EG-VEGF localization to that of VEGF showed that these factors are not localized to the same cell types, but rather show complementary localizations (Figure 1).

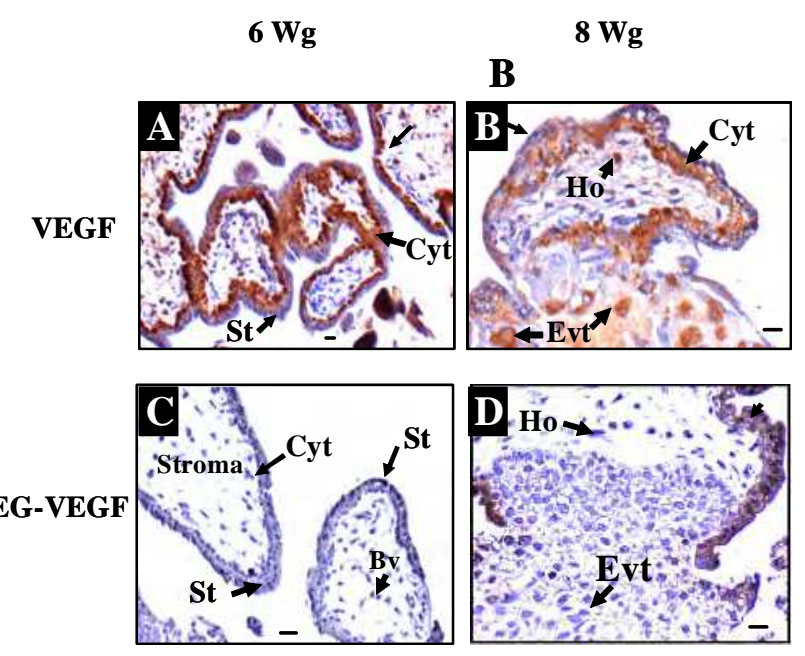

Fig. 1. Comparison of VEGF and EG-VEGF Immunoreactivity (Ir) in placental villous tissues. A, B show representative VEGF Ir, (brown color) at 6 and 8 weeks of gestation (wg), respectively. C, D show EG-VEGF Ir (brown color) at the same wg. Note that VEGF staining is present from $6 \mathrm{wg}$ and EG-VEGF staining is only present at $8 \mathrm{wg}$. EG-VEGF and VEGF exhibit complementary sites of Ir in chorionic villi and EVT. Cytotrophoblast (Ct), Hobfauer cells (Ho), Extravillous trophoblast (EVT), syncytiotrophoblast (St). Scale bar $=20 \mu \mathrm{m}$ 
EG-VEGF receptors were found in trophoblast cells, endothelial cells and EVT, suggesting potential roles of this factor in the control of placental development (Hoffmann et al., 2007, 2006). Using quantitative RT-PCR we determined the pattern of expression of EG-VEGF and its receptors during the first trimester of human pregnancy. PROKR1 expression exhibited the same profile of expression as EG-VEGF, and PROKR2 was stably expressed during the first trimester with a slight increase by the end of this period (Figure.2).

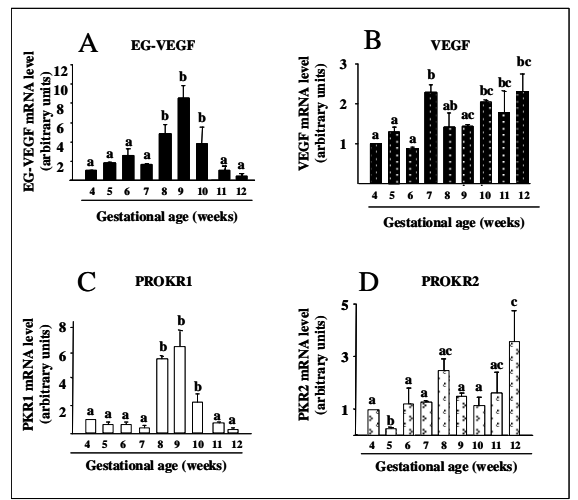

Fig. 2. EG-VEGF (A), VEGF (B), PROKR1 (C) and PROKR2 (D) mRNA expression during the first trimester of pregnancy. Values overwritten with different letters are significantly different from each other $(\mathrm{P}<0.05)$.

The same results were found in mouse placenta during the first 10.5 days post coitum (dpc), corresponding to the first trimester of human pregnancy (Figure.3). We showed that EGVEGF and VEGF exhibit different patterns of expression and different localizations in the mouse placenta. EG-VEGF was mainly localized in the labyrinth whereas VEGF was present in glycogen and giant cells. EG-VEGF mRNA and protein levels were the highest before 10.5 dpc whereas those of VEGF showed stable expression throughout gestation. PROKR1 protein was localized to the labyrinth layer and showed the same pattern of expression as EG-VEGF, whereas PROKR2 expression was maintained over $10.5 \mathrm{dpc}$ with both trophoblastic and endothelial cell localizations. Altogether these findings suggest that EGVEGF may have a direct effect on both endothelial and trophoblast cells and is likely to play an important role in placentation (Hoffmann et al., 2007, 2006).

\subsection{Role of EG-VEGF in the trophoblast invasion}

In the light of the data obtained in our first publications on the expression of this factor and its receptors, we decided to investigate the potential role of EG-VEGF in the control of trophoblast invasion into the maternal decidua, a requisite process for successful pregnancy. Human placental explants and EVT were used to determine EG-VEGF effect on migration, invasion and tube-like organization of EVT. We used the HTR-8/SVneo cells as a model for EVT cells (Graham et al., 1993). A wound healing assay was performed to examine the effect of EGVEGF on HTR motility. Cells were seeded in equal number into six-well plates. At confluence, cells were scratched and allowed to heal for $24 \mathrm{~h}$. Our results showed that EG-VEGF is a potent inhibitor of EVT and migration. Measurement of EVT tube-like formation was performed 


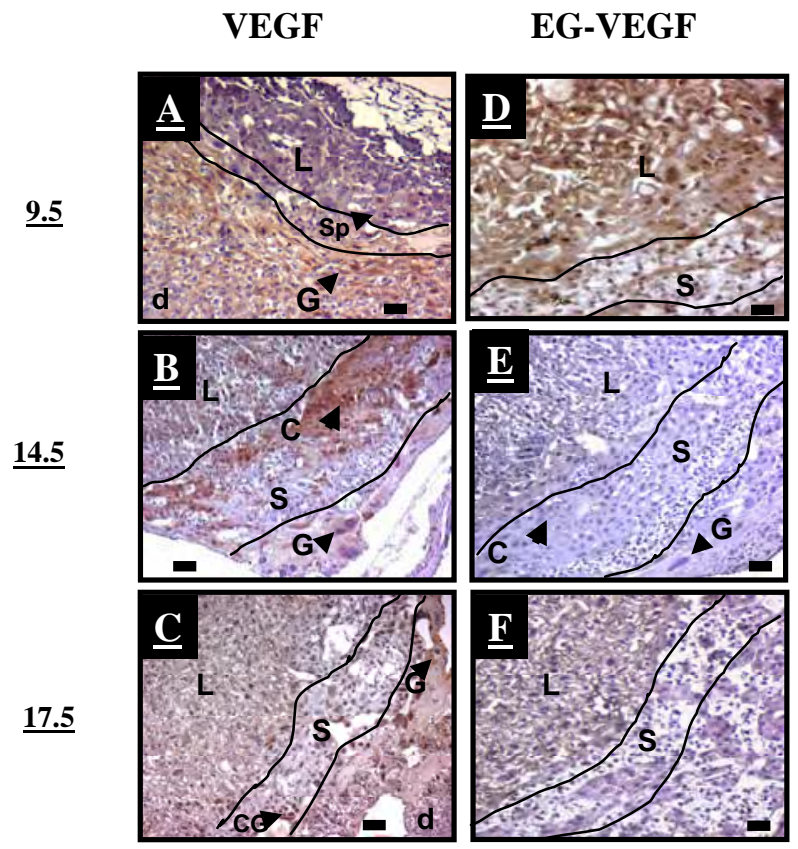

Fig. 3. Immunolocalizations of VEGF and EG-VEGF in mouse placenta. at 9.5, 14.5 and 17.5 dpc. Labyrinth (L), Glycogen cells (GC), Giant cells (Gi), spongiotrophoblast (Sp). Scale bar $=50 \mu \mathrm{m}$

using time lapse microscopy. Our results showed that EG-VEGF inhibited the tube-like organization of EVT cells. The control of EVT invasion by EG-VEGF was confirmed in a set of experiments that employed placental explants. Villous explant cultures were established from first trimester human placentas (10-12 wg) as described previously (Caniggia et al., 1999, Genbacev et al., 1993). It was particularly relevant to study EG-VEGF effects on trophoblast differentiation towards an invasive phenotype in a system in which the placental villous tissue architecture is maintained. Placental villous explants in culture preserve the topology of intact villi and closely mimic the formation of anchoring villi occurring in vivo by the end of first trimester of pregnancy (Caniggia et al., 1999, Genbacev et al., 1993). Figure. 4 shows representative photographs of placental villous tips at day 3 of culture in the absence or presence of EG-VEGF $(50 \mathrm{ng} / \mathrm{ml})$. In the control condition there was an obvious outgrowth of EVT from the distal end of the villous tip and migration into Matrigel. In contrast, in the presence of EG-VEGF, there was almost no outgrowth or migration of EVT into Matrigel. In additional experiments we demonstrated that these effects were mediated by the type 2 receptor of EG-VEGF, PROKR2 and involved MMP2 and 9 activities, (Hoffmann et al., 2009).

\subsection{Role of EG-VEGF in placental angiogenesis.}

Pro-angiogenic effects of EG-VEGF were reported in many reproductive systems, confirming its direct involvement in angiogenesis. Using appropriate angiogenesis assays 


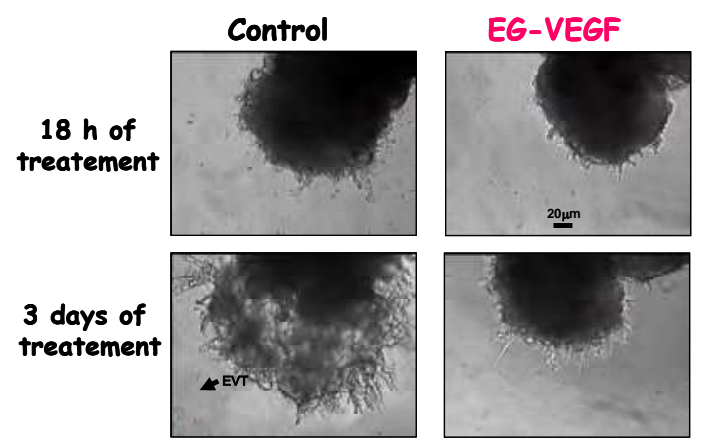

Fig. 4. Effect of EG-VEGF on the invasion of EVT. Villous explants from 10 to $12 \mathrm{wg}$ were maintained in culture for 6 days. EG-VEGF $(50 \mathrm{ng} / \mathrm{ml})$ treatment started $24 \mathrm{~h}$ after the launch of the culture and was assessed for $24 \mathrm{~h}$. Control experiments were run in parallel using explants from the same placenta.

(Proliferation, migration, pseudo-vascular organization, spheroid sprouting) and functional studies (microvascular permeability and paracellular transport) we were able to answer an important biological question related to the role of EG-VEGF in placental development. EGVEGF effects were analyzed in placental microvascular endothelial cells "HPEC" and in macrovascular umbilical vein endothelial cells "HUVEC". First, we showed that HPEC and HUVEC express both types of receptors, with a much higher level of expression in HPEC, (Brouillet et al., 2010). Furthermore, we showed that EG-VEGF increased HPEC but not HUVEC proliferation and migration (Brouillet et al., 2010).

To determine EG-VEGF effect on the sprout formation, a three-dimensional in vitro angiogenesis system was used. Whereas no effect of EG-VEGF was observed on HUVEC sprouting, this factor increases HPEC sprouting. Figure. 5 shows representative photographs of HPEC spheroids at the time of their incubation and $12 \mathrm{~h}$ later. To control the response of the cells, we examined the effect of the potent angiogenic factors, FGF-2. As expected, FGF-2 induced significant sprouting of the spheroids as compared to the control conditions. EG-VEGF induced the same level of sprouting in HPEC spheroids compared to that obtained with FGF2.

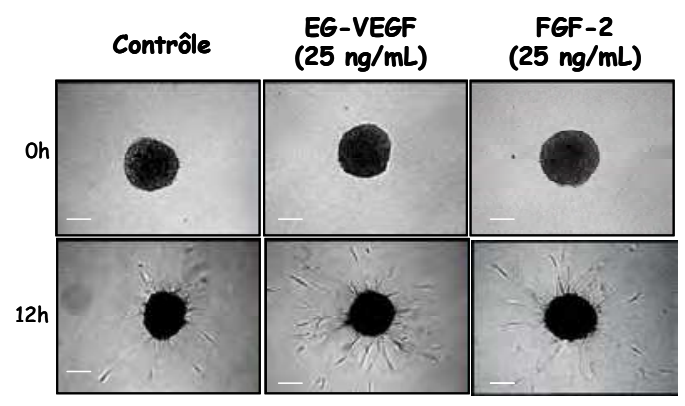

Fig. 5. EG-VEGF, effect on the sprouting of HPEC spheroids. Representative photographs of spheroids formed from HPEC cells and cultured in collagen gel for 0 or $12 \mathrm{~h}$ in the absence or presence of EG-VEGF (25ng/ml), FGF-2 (25 ng/ml). 
In the placenta, the microvascular endothelium is known to participate in angiogenesis, maintenance of blood fluidity and is also a discriminating barrier in materno-fetal transports of solutes and nutrients (Murray, 2003, Rodgers, 1988), therefore a maintenance of a semipermeable barrier by the endothelium is critically important in endothelial cell function. Both permeability and paracellular transport of HPEC monolayers were assessed. HPEC permeability was measured in response to EG-VEGF and thrombin, an enhancer of electrolyte transport. The endothelial barrier was evaluated by trans-endothelial electrical resistance (TEER). Figure. 6A shows the percentage of increase in permeability of a monolayer of HPEC in response to thrombin $(70 \mathrm{U} / \mathrm{ml})$, EG-VEGF $(25 \mathrm{ng} / \mathrm{ml})$, or VEGF (25 $\mathrm{ng} / \mathrm{ml}$ ). TEER was recorded every $5 \mathrm{~min}$ for $35 \mathrm{~min}$. As expected, thrombin significantly increased HPEC permeability. Under EG-VEGF treatment, HPEC permeability increased as early as $5 \mathrm{~min}$ after treatment and was maintained for up to 20 minutes. The effect of EGVEGF on the paracellular transport was measured using $\left[{ }^{3} \mathrm{H}\right]$-mannitol. The data summarizing the permeability coefficients for $\left[{ }^{3} \mathrm{H}\right]$-mannitol transport in response to thrombin and EG-VEGF are presented in Figure. 6B. The basal permeability Coefficient (Papp) in HPEC was $1.7 \times 10^{-5} \mathrm{~cm} / \mathrm{s}$. Thrombin almost doubled $\left[{ }^{3} \mathrm{H}\right]$-mannitol transport through HPEC, and EG-VEGF increased this transport to almost the same levels achieved by

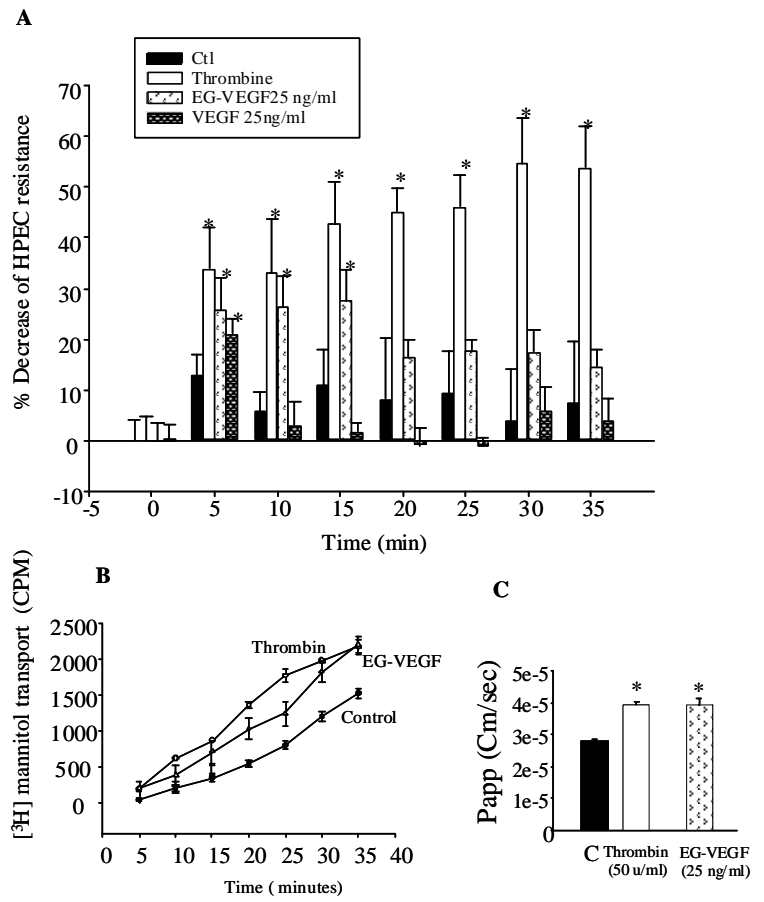

Fig. 6. Effects of EG-VEGF, VEGF and thrombin on the trans-endothelial electrical resistance (TEER) across HPEC monolayers. A Represents the decrease in the TEER of HPEC cells following their incubation with EG-VEG, VEGF or thrombin. The results were normalized to the respective controls. (B). Effects of EG-VEGF and thrombin on the paracellular transport of $\left[{ }^{3} \mathrm{H}\right]$-mannitol in HPEC cells. (C) Represents the permeability coefficient of EG-VEGF and thrombin. 
thrombin, Figure. 6C. More importantly, using siRNA and antibody blocking techniques, we demonstrated that PROKR1 mediates EG-VEGF angiogenic effects, whereas PROKR2 is rather involved in its effects on cellular permeability (Brouillet et al, 2010). Altogether, our results showed, for the first time, that EG-VEGF is a potent new angiogenic and survival factor for microvascular endothelial cells, and characterized the EG-VEGF mediated angiogenic processes. These finding propose a novel view of the regulation of angiogenesis normal placentation, (Brouillet et al, 2010).

\subsection{EG-VEGF regulation in human placenta}

\subsubsection{Regulation by oxygen tension}

Low oxygen tension is a key parameter that controls gene expression during the first trimester of pregnancy. Moreover, the highest level of expression level of EG-VEGF and its receptor PROKR1 is observed during the hypoxic period of human placentation (Hoffmann et al., 2007, 2006). This observation prompted us to hypothesize that EG-VEGF and PROKR1 mRNA might be regulated by oxygen tension in human trophoblast cells. To test this hypothesis, we incubated trophoblast cells isolated from first trimester placentas under either $20 \%$ O2 or $3 \%$ O2 and measured EG-VEGF and PROKR1 mRNA abundance using quantitative RT-PCR. As shown in Figure. 7A, a significant increase in both EG-VEGF (160\% of normoxic control) and PROKR1 (200\% of normoxic control) mRNA levels was observed under hypoxic conditions ( $3 \% \mathrm{O} 2)$. We then examined the effects of transcription and translation inhibitors on the hypoxic regulation of EG-VEGF expression. In the presence of the RNA polymerase inhibitor DRB, the hypoxic induction of EG-VEGF was completely abolished, whereas it was preserved in the presence of cycloheximide, a potent inhibitor of translation, Figure. 7B. These data suggest that hypoxia regulates EG-VEGF gene expression at the transcriptional level.

EG-VEGF levels appeared to greatly vary during early pregnancy, progressively increasing until the $10^{\text {th }} \mathrm{wg}$ and rapidly dropping afterward. These dramatic changes appear to be correlated with the hypoxic developmental period of the placenta. This correlation is supported by the transcriptionally controlled up-regulation of EG-VEGF mRNA and concomitant increase of its protein levels that were observed in primary cultures of trophoblasts after $24 \mathrm{~h}$ of culture under reduced oxygen tension. This regulation was not unexpected as a functional hypoxia-response element (TACGTGCGGC) able to bind the hypoxia-inducible factor-1 has been identified in the human EG-VEGF promoter (LeCouter et al., 2001). Regulation of placental growth factors expression by oxygen tension is well established and has been described for several angiogenic factors, including VEGF, TGF $\beta 3$ (Schaffer et al., 2003), and the soluble form of VEGF receptor-1 (s-flt) (H. Li et al., 2005, Nagamatsu et al., 2004). We also observed up-regulation of PROKR1 receptor expression under hypoxic conditions. A GenBank screen of the human PROKR1 promoter revealed the presence of one putative HIF-1 $\alpha$ binding site, suggesting that the oxygen effect on PROKR1 expression might occur through a pathway that involves HIF-1 $\alpha$. However, we cannot totally exclude that other factors presenting peaks in their expression during the first trimester of pregnancy may also participate in the regulation of EG-VEGF expression. Human chorionic gonadotropin (hCG) and progesterone are two such candidates because they have been recently shown to stimulate EG-VEGF mRNA expression in human 
luteinized granulosa cells (Fraser et al., 2005) and human endometrial tissue (Battersby et al., 2004), respectively.
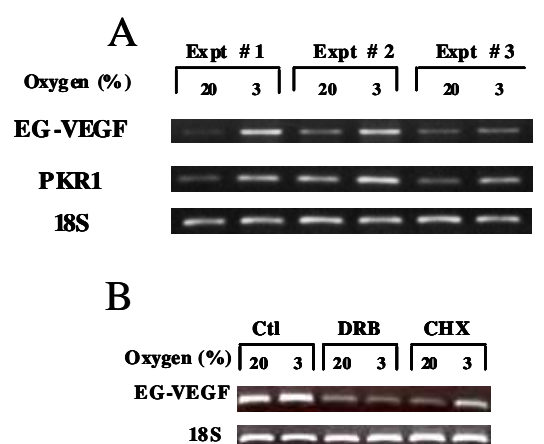

Fig. 7. Effect of hypoxia on EG-VEGF and PROKR1 mRNA expression in human

trophoblast cells. Cytrophoblasts were isolated from 10 different placentas collected at 7-10 weeks of gestation and cultured under either normoxic or hypoxic conditions. Panel A shows the RT-PCR amplification products for EG-VEGF and PROKR1 under either $20 \%$ or $3 \% \mathrm{O}_{2}$. B. shows the effect of DRB and CHX on basal and hypoxia-induced EG-VEGF mRNA expression in trophoblast cells.

\subsubsection{Regulation by human chorionic gonadotropin (hCG)}

During placental development, the hypoxic environment occurs from the beginning of implantation to the end of the first trimester. However, the strongest expression of EGVEGF is between the $8^{\text {th }}$ and $11^{\text {th }} \mathrm{wg}$, suggesting that other factors than hypoxia might regulate the EG-VEGF/ PROKR1/PROKR2 system. To date, little is known about the regulation of EG-VEGF and its receptors, and there is no enlightenment for the peak of expression of EG-VEGF by the end of the first trimester of pregnancy. During the first trimester of pregnancy, one dominant hormone, hCG exhibits the same pattern of expression as of EG-VEGF and displays similar effects on placental development (Licht et al., 2001, Malassine \& Cronier, 2002). One of the earliest endocrine roles of hCG is to stimulate the corpus luteum to produce enough progesterone in order to establish pregnancy at the outset. In the placenta, hCG is well known to facilitate trophoblastic differentiation (Licht et al., 2001, Malassine \& Cronier, 2002), and was reported to induce the expression of specific genes such as VEGF, leukemia inhibitory factor, and MMP-9, all central to the establishment of the feto-maternal interface (Licht et al., 2007, Zygmunt et al., 2002). In human placenta, hCG is primarily produced by the syncytiotrophoblast and to a certain extent by the cytotrophoblast (Kirkegaard et al., 2011, Krantz et al., 2004, Rao \& Lei, 2007, Shi et al., 1993). In normal pregnancies, detectable levels of hCG begin to appear in the maternal circulation about 2-3 weeks after conception and the peak is observed at $\sim 8-9$ wg before declining significantly in the later stages of pregnancy. High serum hCG levels at mid-late pregnancy have been associated with PE, IUGR and Down's syndrome (DS).

We investigated the regulation of EG-VEGF expression, and its receptors by hCG. Both placental explants (PEX) and primary cultures of trophoblast from the first trimester of 
pregnancy were used to investigate this hypothesis. Our results show that i) LH/CGR, the hCG receptor, is expressed both in cyto- and syncytiotrophoblasts ii) hCG increases EGVEGF, PROKR1 and PROKR2 mRNA and protein expression in a dose and time-dependent manners iii) hCG increases the release of EG-VEGF from PEX conditioned media iv) hCG effects are transcriptional and post- transcriptional and $\mathbf{v}$ ) the hCG effects are mediated by cAMP via cAMP response elements present in the EG-VEGF promoter region. Altogether, these results demonstrate a new role for hCG in the regulation of an emerging regulatory system of trophoblast invasion, EG-VEGF and its receptors (Figure 8).
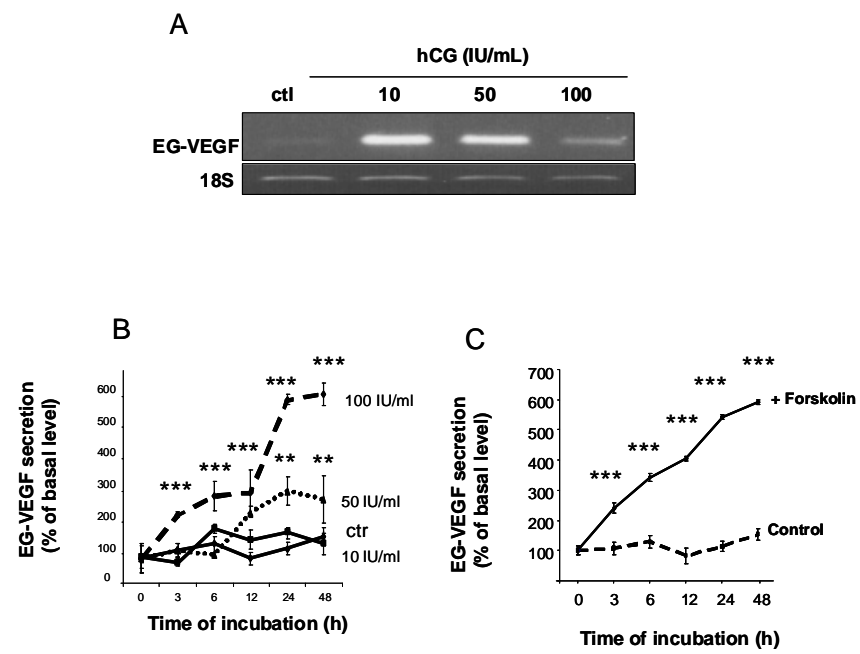

Fig. 8. hCG effect on EG-VEGF expression and secretion. A shows a representative analysis of hCG $(10,50$ and $100 \mathrm{IU} / \mathrm{ml})$ effect on EG-VEGF mRNA expression in syncytiotrophoblast cells. B shows a temporal ( 0 to $48 \mathrm{~h}$ ) and a dose dependence analysis of hCG effect on EG-VEGF secretion in placental conditioned media. $C$ shows a time course (0h-48h) effect of Forskolin on EG-VEGF secretion.

\section{EG-VEGF and pregnancy pathologies}

\subsection{Prematurity}

Compelling recent findings suggest that PROKs and their receptors might play a crucial role in premature onset of labor. The labor onset is known to be associated with inflammatory cascades in the uteroplacental unit, and EG-VEGF has been shown to regulate the production of proinflammatory cytokines and to be involved in the inflammatory response in the placenta (Catalano et al., 2010 , Denison et al., 2008, Evans et al., 2008). Therefore, antagonism of prokineticin action may provide a therapy for preterm labor caused by early inflammation and contractile pathways. Further investigations are however required to demonstrate a direct involvement of EG-VEGF in the mechanisms of term and preterm labor. A particular interest should be given to EG-VEGF potential actions on the expression of factors that trigger parturition, particularly in the fetal membranes, major sites of prostaglandins synthesis and metabolism. 


\subsection{Preeclampsia and IUGR.}

\subsubsection{EG-VEGF and Preeclampsia}

Since the discovery of EG-VEGF, our group has been interested in its study in PE. In fact, the combination of our previous data showing that EG-VEGF was abundantly expressed in human placenta during the first trimester of pregnancy; that its expression was up regulated by hypoxia; and that EG-VEGF regulates EVT invasion, suggested to us that EG-VEGF circulating levels might be altered in PE. We were first to report EG-VEGF circulating levels throughout human pregnancy and to show that they were significantly higher during the third trimester of pregnancy in PE patients compared to controls (Figure 9). These data raise the possibility that inappropriate expression or function of EG-VEGF or that of its receptors might contribute to major complications of pregnancy, such as PE, which is associated with abnormal trophoblast invasion and placental development. We now know that the origin of PE takes place during the first trimester of pregnancy and that any changes in protein expression after the establishment of the disease are considered to be consequences of the disease rather than causes of its development. Our data show that EG-VEGF expression is at its lowest levels by the end of the first trimester, suggesting that its greatest role should occur within that trimester. Moreover, given the correlation between the pattern of EGVEGF and PROKR1 expression with the hypoxic period of placental development and knowing that failure in placental angiogenesis is thought to contribute to PE development, one can speculate on the potential implication of this factor and/or its receptors in the development of PE. However, only a prospective study examining the expression of EGVEGF and/or PROKR1 during the first trimester of pregnancy in women who go on to develop PE will allow to provide an answer to this question. Clinical studies are ongoing to examine these hypotheses. Future studies are also required to determine the biological activities triggered by EG-VEGF in the human placenta and identify whether dysregulation of EG-VEGF expression may result in placental pathologies.
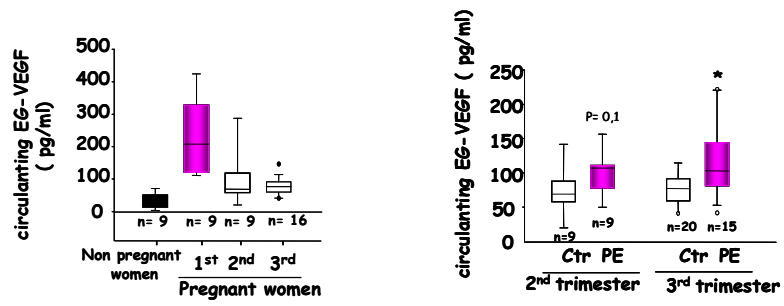

Fig. 9. EG-VEGF serum levels in non-pregnant and in pregnant women at the first, second and third trimesters. (graph on the left) and in PE women at second and third trimesters. Box plot demonstrates 10 th, 25 th, 50 th, 75 th, and 90 th percentiles. $\left({ }^{*} \mathrm{P}<0.05\right.$, by ANOVA followed by Dunn's Method).

\subsubsection{EG-VEGF and IUGR}

Nowadays, our group has been interested in the study of the direct effects of EG-VEGF on placental development and particularly on its direct actions on the villi growth and survival, under stressful conditions. These studies were performed in the perspective to investigate the role of EG-VEGF in the second most important pathology of human pregnancy, IUGR. 
Hence, we investigated EG-VEGF effects on i) trophoblast proliferation, both in primary cytotrophoblast (CT) and in placental explants culture, and on trophoblast survival, ii) cytotrophoblast syncytialisation (measurement of syncytin 1 and 2 and $\beta$-hCG mRNA expression). To further investigate the role of EG-VEGF and its receptors in placental development, we determined their levels of expression, both at the mRNA and protein levels, in normal and IUGR placentas. We also determined the circulating levels of EGVEGF in sera collected from normal and IUGR pregnant women. Our results show that EGVEGF i) increased CT proliferation; both in primary and explant cultures ii) did not affect syncytin 1, syncytin 2 and $\beta$-hCG mRNA expression iii) EG-VEGF, PROKR1 and PROKR2 mRNA and proteins levels are significantly increased in IUGR placentas, and iv) EG-VEGF circulating levels are significantly higher in IUGR patients. Altogether, these results identify a new placental growth factor during the first trimester of pregnancy, and provide evidence for its dysregulation in IUGR placentas. Changes in EG-VEGF, PROKR1 and PROKR2 in IUGR placentas, may well occur as a compensatory mechanism for this pathological condition. Further clinical investigations are required to demonstrate whether dysregulations in EG-VEGF and receptors in IUGR pregnancies are causes or consequences of the occurrence of this pathology.

\section{Future directions for research on EG-VEGF in human placentation}

\subsection{EG-VEGF and implantation}

It has been demonstrated that EG-VEGF, but not PROK2, expression peaks during the midluteal window of implantation, with immunolocalization to endometrial glandular epithelium, stromal and endothelial cells, and myometrial vascular endothelium as well as smooth muscle (Evans et al., 2009,Ngan et al., 2006,Salker et al.). In addition, it has been suggested that EG-VEGF could have a role in mediating the dysregulated vascular permeability that occur in ovarian hyperstimulation syndrome. The expression of PROKs and their receptors has also been reported in the fallopian tube from women with ectopic pregnancy (Tiberi et al.,2010). A dysregulation of these factors and their receptors has been demonstrated, suggesting a potential role for PROKs in fallopian tube function (Shaw et al.,2010). It has been postulated that these dysregulations could affect smooth muscle contractility in fallopian tube and embryo-tubal transport, providing a potential cause for ectopic pregnancy. More studies are required to evaluate whether PROKs are involved in these processes.

We have shown that EG-VEGF acts as a permeability factor during the first trimester of pregnancy, one can therefore speculate that EG-VEGF might also act on the endometrium to facilitate implantation by increasing endothelial leakage at the implantation site, one of the earliest signs of implantation. More studies are also required to evaluate whether PROKs are involved in perimplantation, spiral arteriole formation and recruitment of immune cells, including uterine natural killer cells, which have been shown to increase in number during the implantation window and in early pregnancy (King et al., 1996a, King et al., 1996b).

\subsection{EG-VEGF and preeclampsia}

Although there is abundant evidence for the role of circulating anti-angiogenic factors as mediators of the clinical signs and symptoms of PE (Ahmed et al., 2000), there are no 
definitive data linking early abnormalities in angiogenic factors with the impaired placentation in PE. Nowadays, our team is conducting a clinical study that aims to answer this question for EG-VEGF. This work relies on using blood samples collected from 500 pregnant women during early pregnancy with a follow up of their pregnancies outcome. A positive correlation between high EG-VEGF levels and PE occurrence will suggest that this factor is directly involved in alterations that lead to PE development. Moreover, it will suggest that sequential measurement of anti-angiogenic factors may be useful as a screening test for premature PE, possibly when combined with other early predictive tests such as Doppler ultrasound (Grill et al., 2009). This will be important for timely referral of patients at high risk of developing early PE and for indicating the need for therapeutic measures when they become available. Large prospective studies with longitudinal specimen collection from early pregnancy are required to definitely assess whether sequential changes in angiogenic proteins can be used to predict preterm PE.

\section{Conclusion}

During the last six years, we were able to assemble interesting data in regards to the expression, role and regulation of EG-VEGF in normal and pathological human pregnancies. The combination between our fundamental research and clinical approaches allowed us to strongly propose EG-VEGF as a potential marker for PE. Our ongoing clinical study will allow us to undeniably determine the role of this factor in normal placentation and to conclude on its potential relevance as a marker of PE. Furthermore we plan to develop an animal model to test whether dysregulations in EG-VEGF levels are a cause or consequence of the development of this pathology.

\section{Acknowledgments}

We thank the staff of the Department of Gynecology/Obstetrics, Grenoble Hospital (Pr. F. Sergent). We acknowledge the following sources of funding: INSERM (U1036), University Joseph Fourier, CEA, Région Rhône-Alpes (CIBLE-2008) and the Fondation pour la Recherche Médicale.

\section{References}

Ahmed, A.; Dunk, C.; Ahmad, S. et al. (2000). Regulation of placental vascular endothelial growth factor (VEGF) and placenta growth factor (PIGF) and soluble Flt-1 by oxygen--a review, Placenta, Vol.21 Suppl A, pp. S16-24

Aplin, J.D. (1991). Implantation, trophoblast differentiation and haemochorial placentation: mechanistic evidence in vivo and in vitro, J Cell Sci, Vol.99 (Pt 4), pp. 681-692

Battersby, S.; Critchley, H.O.; Morgan, K. et al. (2004). Expression and regulation of the prokineticins (endocrine gland-derived vascular endothelial growth factor and Bv8) and their receptors in the human endometrium across the menstrual cycle, $J$ Clin Endocrinol Metab, Vol.89, No.5, pp. 2463-2469

Boisbouvier, J.; Albrand, J.P.; Blackledge, M. et al. (1998). A structural homologue of colipase in black mamba venom revealed by NMR floating disulphide bridge analysis, J Mol Biol, Vol.283, No.1, pp. 205-219

Brouillet, S.; Hoffmann, P.; Benharouga, M. et al. Molecular characterization of EG-VEGFmediated angiogenesis: differential effects on microvascular and macrovascular endothelial cells, Mol Biol Cell, Vol.21, No.16, pp. 2832-2843 
Caniggia, I.; Grisaru-Gravnosky, S.; Kuliszewsky, M. et al. (1999). Inhibition of TGF-beta 3 restores the invasive capability of extravillous trophoblasts in preeclamptic pregnancies, J Clin Invest, Vol.103, No.12, pp. 1641-1650

Caniggia, I.; Taylor, C.V.; Ritchie, J.W. et al. (1997). Endoglin regulates trophoblast differentiation along the invasive pathway in human placental villous explants, Endocrinology, Vol.138, No.11, pp. 4977-4988

Cartwright, J.E.; Holden, D.P.\& Whitley, G.S. (1999). Hepatocyte growth factor regulates human trophoblast motility and invasion: a role for nitric oxide, $\mathrm{Br}$ J Pharmacol, Vol.128, No.1, pp. 181-189

Carty, D.M.; Delles, C.\& Dominiczak, A.F. (2010) Preeclampsia and future maternal health, J Hypertens, Vol.28, No.7, pp. 1349-1355

Catalano, R.D.; Lannagan, T.R.; Gorowiec, M. et al. (2010) Prokineticins: novel mediators of inflammatory and contractile pathways at parturition?, Mol Hum Reprod, Vol.16, No.5, pp. 311-319

Charnock-Jones, D.S.; Kaufmann, P.\& Mayhew, T.M. (2004). Aspects of human fetoplacental vasculogenesis and angiogenesis. I. Molecular regulation, Placenta, Vol.25, No.2-3, pp. 103-113

Cook, I.H.; Evans, J.; Maldonado-Perez, D. et al. Prokineticin-1 (PROK1) modulates interleukin (IL)-11 expression via prokineticin receptor 1 (PROKR1) and the calcineurin/NFAT signalling pathway, Mol Hum Reprod, Vol.16, No.3, pp. 158-169

Cross, J.C.; Werb, Z.\& Fisher, S.J. (1994). Implantation and the placenta: key pieces of the development puzzle, Science, Vol.266, No.5190, pp. 1508-1518

Dekker, G.A. (1999). Risk factors for preeclampsia, Clin Obstet Gynecol, Vol.42, No.3, pp. 422435

Dellian, M.; Witwer, B.P.; Salehi, H.A. et al. (1996). Quantitation and physiological characterization of angiogenic vessels in mice: effect of basic fibroblast growth factor, vascular endothelial growth factor/vascular permeability factor, and host microenvironment, Am J Pathol, Vol.149, No.1, pp. 59-71

Denison, F.C.; Battersby, S.; King, A.E. et al. (2008). Prokineticin-1: a novel mediator of the inflammatory response in third-trimester human placenta, Endocrinology, Vol.149, No.7, pp. 3470-3477

Dode, C.; Teixeira, L.; Levilliers, J. et al. (2006). Kallmann syndrome: mutations in the genes encoding prokineticin-2 and prokineticin receptor-2, PLoS Genet, Vol.2, No.10, pp. e175

Dorsch, M.; Qiu, Y.; Soler, D. et al. (2005). PK1/EG-VEGF induces monocyte differentiation and activation, J Leukoc Biol, Vol.78, No.2, pp. 426-434

Evans, J.; Catalano, R.D.; Brown, P. et al. (2009). Prokineticin 1 mediates fetal-maternal dialogue regulating endometrial leukemia inhibitory factor, FASEB J, Vol.23, No.7, pp. $2165-2175$

Evans, J.; Catalano, R.D.; Morgan, K. et al. (2008). Prokineticin 1 signaling and gene regulation in early human pregnancy, Endocrinology, Vol.149, No.6, pp. 2877-2887

Fisher, S.J. (2004). The placental problem: linking abnormal cytotrophoblast differentiation to the maternal symptoms of preeclampsia, Reprod Biol Endocrinol, Vol.2, pp. 53

Fraser, H.M.; Bell, J.; Wilson, H. et al. (2005). Localization and quantification of cyclic changes in the expression of endocrine gland vascular endothelial growth factor in the human corpus luteum, J Clin Endocrinol Metab, Vol.90, No.1, pp. 427-434

Genbacev, O.; Jensen, K.D.; Powlin, S.S. et al. (1993). In vitro differentiation and ultrastructure of human extravillous trophoblast (EVT) cells, Placenta, Vol.14, No.4, pp. 463-475 
Graham, C.H.; Hawley, T.S.; Hawley, R.G. et al. (1993). Establishment and characterization of first trimester human trophoblast cells with extended lifespan, Exp Cell Res, Vol.206, No.2, pp. 204-211

Graham, C.H.\& Lala, P.K. (1991). Mechanism of control of trophoblast invasion in situ, J Cell Physiol, Vol.148, No.2, pp. 228-234

Grill, S.; Rusterholz, C.; Zanetti-Dallenbach, R. et al. (2009). Potential markers of preeclampsia--a review, Reprod Biol Endocrinol, Vol.7, pp. 70

Hoffmann, P.; Feige, J.J.\& Alfaidy, N. (2007). Placental expression of EG-VEGF and its receptors PKR1 (prokineticin receptor-1) and PKR2 throughout mouse gestation, Placenta, Vol.28, No.10, pp. 1049-1058

Hoffmann, P.; Feige, J.J.\& Alfaidy, N. (2006). Expression and oxygen regulation of endocrine gland-derived vascular endothelial growth factor/prokineticin-1 and its receptors in human placenta during early pregnancy, Endocrinology, Vol.147, No.4, pp. 1675-1684

Hoffmann, P.; Saoudi, Y.; Benharouga, M. et al. (2009). Role of EG-VEGF in human placentation: Physiological and pathological implications, J Cell Mol Med, Vol.13, No.8B, pp. 2224-2235

Hoogerwerf, W.A. (2006). Prokineticin 1 inhibits spontaneous giant contractions in the murine proximal colon through nitric oxide release, Neurogastroenterol Motil, Vol.18, No.6, pp. $455-463$

Huppertz, B.\& Peeters, L.L. (2005). Vascular biology in implantation and placentation, Angiogenesis, Vol.8, No.2, pp. 157-167

Ilekis, J.V.; Reddy, U.M.\& Roberts, J.M. (2007). Preeclampsia--a pressing problem: an executive summary of a National Institute of Child Health and Human Development workshop, Reprod Sci, Vol.14, No.6, pp. 508-523

Irgens, L.M. (2007). Commentary: on the clinical prediction of pre-eclampsia and its enigmatic aetiology, Int J Epidemiol, Vol.36, No.2, pp. 420-421

Irving, J.A.\& Lala, P.K. (1995). Functional role of cell surface integrins on human trophoblast cell migration: regulation by TGF-beta, IGF-II, and IGFBP-1, Exp Cell Res, Vol.217, No.2, pp. 419-427

Jauniaux, E.; Watson, A.L.; Hempstock, J. et al. (2000). Onset of maternal arterial blood flow and placental oxidative stress. A possible factor in human early pregnancy failure, Am J Pathol, Vol.157, No.6, pp. 2111-2122

King, A.; Burrows, T.\& Loke, Y.W. (1996a). Human uterine natural killer cells, Nat Immun, Vol.15, No.1, pp. 41-52

King, A.; Jokhi, P.P.; Burrows, T.D. et al. (1996b). Functions of human decidual NK cells, Am J Reprod Immunol, Vol.35, No.3, pp. 258-260

Kingdom, J.; Huppertz, B.; Seaward, G. et al. (2000). Development of the placental villous tree and its consequences for fetal growth, Eur J Obstet Gynecol Reprod Biol, Vol.92, No.1, pp. 35-43

Kirkegaard, I.; Henriksen, T.B.\& Uldbjerg, N. (2011). Early fetal growth, PAPP-A and free beta-hCG in relation to risk of delivering a small-for-gestational age infant, Ultrasound Obstet Gynecol, Vol.37, No.3, pp. 341-347

Kisliouk, T.; Levy, N.; Hurwitz, A. et al. (2003). Presence and regulation of endocrine gland vascular endothelial growth factor/prokineticin-1 and its receptors in ovarian cells, J Clin Endocrinol Metab, Vol.88, No.8, pp. 3700-3707

Krantz, D.; Goetzl, L.; Simpson, J.L. et al. (2004). Association of extreme first-trimester free human chorionic gonadotropin-beta, pregnancy-associated plasma protein A, and 
nuchal translucency with intrauterine growth restriction and other adverse pregnancy outcomes, Am J Obstet Gynecol, Vol.191, No.4, pp. 1452-1458

LeCouter, J.; Kowalski, J.; Foster, J. et al. (2001). Identification of an angiogenic mitogen selective for endocrine gland endothelium, Nature, Vol.412, No.6850, pp. 877-884

LeCouter, J.; Lin, R.; Tejada, M. et al. (2003). The endocrine-gland-derived VEGF homologue Bv8 promotes angiogenesis in the testis: Localization of Bv8 receptors to endothelial cells, Proc Natl Acad Sci U S A, Vol.100, No.5, pp. 2685-2690

Levine, R.J.; Maynard, S.E.; Qian, C. et al. (2004). Circulating angiogenic factors and the risk of preeclampsia, N Engl J Med, Vol.350, No.7, pp. 672-683

Li, H.; Gu, B.; Zhang, Y. et al. (2005). Hypoxia-induced increase in soluble Flt-1 production correlates with enhanced oxidative stress in trophoblast cells from the human placenta, Placenta, Vol.26, No.2-3, pp. 210-217

Li, M.; Bullock, C.M.; Knauer, D.J. et al. (2001). Identification of two prokineticin cDNAs: recombinant proteins potently contract gastrointestinal smooth muscle, $\mathrm{Mol}$ Pharmacol, Vol.59, No.4, pp. 692-698

Licht, P.; Fluhr, H.; Neuwinger, J. et al. (2007). Is human chorionic gonadotropin directly involved in the regulation of human implantation?, Mol Cell Endocrinol, Vol.269, No.1-2, pp. 85-92

Licht, P.; Russu, V.\& Wildt, L. (2001). On the role of human chorionic gonadotropin (hCG) in the embryo-endometrial microenvironment: implications for differentiation and implantation, Semin Reprod Med, Vol.19, No.1, pp. 37-47

Lin, D.C.; Bullock, C.M.; Ehlert, F.J. et al. (2002). Identification and molecular characterization of two closely related $G$ protein-coupled receptors activated by prokineticins/endocrine gland vascular endothelial growth factor, J Biol Chem, Vol.277, No.22, pp. 19276-19280

Lin, R.; LeCouter, J.; Kowalski, J. et al. (2002). Characterization of endocrine gland-derived vascular endothelial growth factor signaling in adrenal cortex capillary endothelial cells, J Biol Chem, Vol.277, No.10, pp. 8724-8729

Lysiak, J.J.; Han, V.K.\& Lala, P.K. (1993). Localization of transforming growth factor alpha in the human placenta and decidua: role in trophoblast growth, Biol Reprod, Vol.49, No.5, pp. 885-894

Malassine, A.\& Cronier, L. (2002). Hormones and human trophoblast differentiation: a review, Endocrine, Vol.19, No.1, pp. 3-11

Maldonado-Perez, D.; Evans, J.; Denison, F. et al. (2007). Potential roles of the prokineticins in reproduction, Trends Endocrinol Metab, Vol.18, No.2, pp. 66-72

Martin, C.; Balasubramanian, R.; Dwyer, A.A. et al. The role of the prokineticin 2 pathway in human reproduction: evidence from the study of human and murine gene mutations, Endocr Rev, Vol.32, No.2, pp. 225-246

Masuda, Y.; Takatsu, Y.; Terao, Y. et al. (2002). Isolation and identification of EGVEGF/prokineticins as cognate ligands for two orphan G-protein-coupled receptors, Biochem Biophys Res Commun, Vol.293, No.1, pp. 396-402

McMaster, M.T.; Zhou, Y.\& Fisher, S.J. (2004). Abnormal placentation and the syndrome of preeclampsia, Semin Nephrol, Vol.24, No.6, pp. 540-547

Murray, J.D. (2003). On the mechanochemical theory of biological pattern formation with application to vasculogenesis, C R Biol, Vol.326, No.2, pp. 239-252

Myatt, L.\& Miodovnik, M. (1999). Prediction of preeclampsia, Semin Perinatol, Vol.23, No.1, pp. $45-57$ 
Nagamatsu, T.; Fujii, T.; Kusumi, M. et al. (2004). Cytotrophoblasts up-regulate soluble fmslike tyrosine kinase- 1 expression under reduced oxygen: an implication for the placental vascular development and the pathophysiology of preeclampsia, Endocrinology, Vol.145, No.11, pp. 4838-4845

Negri, L.; Lattanzi, R.; Giannini, E. et al. (2005). Biological activities of Bv8 analogues, $\mathrm{Br}$ J Pharmacol, Vol.146, No.5, pp. 625-632

Ngan, E.S.; Lee, K.Y.; Yeung, W.S. et al. (2006). Endocrine gland-derived vascular endothelial growth factor is expressed in human peri-implantation endometrium, but not in endometrial carcinoma, Endocrinology, Vol.147, No.1, pp. 88-95

Pasquali, D.; Rossi, V.; Staibano, S. et al. (2006). The endocrine-gland-derived vascular endothelial growth factor (EG-VEGF)/prokineticin 1 and 2 and receptor expression in human prostate: Up-regulation of EG-VEGF/prokineticin 1 with malignancy, Endocrinology, Vol.147, No.9, pp. 4245-4251

Rao, C.V.\& Lei, Z.M. (2007). The past, present and future of nongonadal LH/hCG actions in reproductive biology and medicine, Mol Cell Endocrinol, Vol.269, No.1-2, pp. 2-8

Redman, C.W.\& Sargent, I.L. (2005). Latest advances in understanding preeclampsia, Science, Vol.308, No.5728, pp. 1592-1594

Rodgers, G.M. (1988). Hemostatic properties of normal and perturbed vascular cells, FASEB J, Vol.2, No.2, pp. 116-123

Salker, M.; Teklenburg, G.; Molokhia, M. et al. Natural selection of human embryos: impaired decidualization of endometrium disables embryo-maternal interactions and causes recurrent pregnancy loss, PLoS One, Vol.5, No.4, pp. e10287

Schaffer, L.; Scheid, A.; Spielmann, P. et al. (2003). Oxygen-regulated expression of TGF-beta 3 , a growth factor involved in trophoblast differentiation, Placenta, Vol.24, No.10, pp. 941-950

Shaw, J.L.; Denison, F.C.; Evans, J. et al. (2010) Evidence of prokineticin dysregulation in Fallopian tube from women with ectopic pregnancy, Fertil Steril,

Shi, Q.J.; Lei, Z.M.; Rao, C.V. et al. (1993). Novel role of human chorionic gonadotropin in differentiation of human cytotrophoblasts, Endocrinology, Vol.132, No.3, pp. 1387-1395

Sibai, B.; Dekker, G.\& Kupferminc, M. (2005). Pre-eclampsia, Lancet, Vol.365, No.9461, pp. 785-799

Soga, T.; Matsumoto, S.; Oda, T. et al. (2002). Molecular cloning and characterization of prokineticin receptors, Biochim Biophys Acta, Vol.1579, No.2-3, pp. 173-179

Stewart, P.A.\& Wiley, M.J. (1981). Developing nervous tissue induces formation of bloodbrain barrier characteristics in invading endothelial cells: a study using quail--chick transplantation chimeras, Dev Biol, Vol.84, No.1, pp. 183-192

Strickland, S.\& Richards, W.G. (1992). Invasion of the trophoblasts, Cell, Vol.71, No.3, pp. 355-357

Tiberi, F.; Tropea, A.; Apa, R. et al. (2010) Prokineticin 1 mRNA expression in the endometrium of healthy women and in the eutopic endometrium of women with endometriosis, Fertil Steril, Vol.93, No.7, pp. 2145-2149

Wells, M. (2007). The pathology of gestational trophoblastic disease: recent advances, Pathology, Vol.39, No.1, pp. 88-96

Winkler, M. (2003). Role of cytokines and other inflammatory mediators, BJOG, Vol.110 Suppl 20, pp. 118-123

Zygmunt, M.; Herr, F.; Keller-Schoenwetter, S. et al. (2002). Characterization of human chorionic gonadotropin as a novel angiogenic factor, J Clin Endocrinol Metab, Vol.87, No.11, pp. 5290-5296 


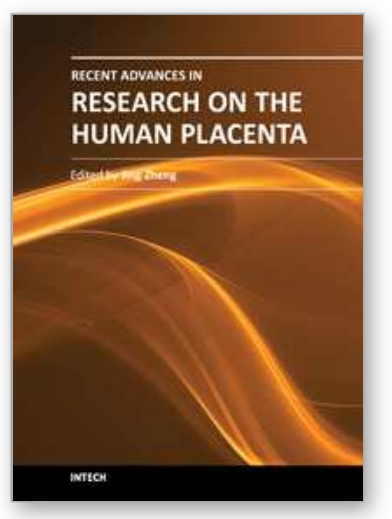

\author{
Recent Advances in Research on the Human Placenta \\ Edited by Dr. Jing Zheng
}

ISBN 978-953-51-0194-9

Hard cover, 428 pages

Publisher InTech

Published online 07, March, 2012

Published in print edition March, 2012

This book contains the total of 19 chapters, each of which is written by one or several experts in the corresponding field. The objective of this book is to provide a comprehensive and most updated overview of the human placenta, including current advances and future directions in the early detection, recognition, and management of placental abnormalities as well as the most common placental structure and functions, abnormalities, toxicology, infections, and pathologies. It also includes a highly controversial topic, therapeutic applications of the human placenta. A collection of articles presented by active investigators provides a clear update in the area of placental research for medical students, nurse practitioners, practicing clinicians, and biomedical researchers in the fields of obstetrics, pediatrics, family practice, genetics, and others who may be interested in human placentas.

\title{
How to reference
}

In order to correctly reference this scholarly work, feel free to copy and paste the following:

P. Hoffmann, S. Brouillet, M. Benharouga, J.J. Feige and N. Alfaidy (2012). Role of EG-VEGF in Human Placentation: Physiological and Pathological Implications, Recent Advances in Research on the Human Placenta, Dr. Jing Zheng (Ed.), ISBN: 978-953-51-0194-9, InTech, Available from: http://www.intechopen.com/books/recent-advances-in-research-on-the-human-placenta/role-of-eg-vegf-inhuman-placentation-physiological-and-pthological-implications

\section{INTECH}

open science | open minds

\section{InTech Europe}

University Campus STeP Ri

Slavka Krautzeka 83/A

51000 Rijeka, Croatia

Phone: +385 (51) 770447

Fax: +385 (51) 686166

www.intechopen.com

\section{InTech China}

Unit 405, Office Block, Hotel Equatorial Shanghai

No.65, Yan An Road (West), Shanghai, 200040, China

中国上海市延安西路65号上海国际贵都大饭店办公楼 405 单元

Phone: +86-21-62489820

Fax: $+86-21-62489821$ 
(C) 2012 The Author(s). Licensee IntechOpen. This is an open access article distributed under the terms of the Creative Commons Attribution 3.0 License, which permits unrestricted use, distribution, and reproduction in any medium, provided the original work is properly cited. 